\title{
Preface: Outline and Problems
}

This book is about peasant leaders and some ways of getting to understand them. Concretely, it describes agrarian leadership and factional politics in a small village of peasants that was still Tarascan Indian at the time of fieldwork, and it tells "how to" by setting forth demystified field methods and writing crafts and strategies. More generally, it explores the meaning of fieldwork by explicitly conjoining two enterprises that are inextricably interconnected. The first is a full exposition of the results of fieldwork, historical research, and write-up, that is, a substantial text of anthropological history. The second is a retrospective, introspective discussion of the personal background, fieldwork practices, and what is called the composition of a text. Of course, the section on ideas and methods contains rich, illustrative description, just as the empirical treatment of a history and a structure says or implies much about method. Incidentally, the more methodologically and theoretically oriented reader is invited to read Part IV first, and then go back to the history, life history, and ethnography of Parts I-III. The book can be read either way, although the order adopted below is somewhat more integrated and cumulative.

Let me outline the main parts of the book. The first third or so goes directly into the biographical character studies or political life histories of seven of the local leaders as they were seen and envisaged in the field in $1955^{-1956}$ (indeed, four of these texts are pretty much what was written during the year following that fieldwork). Each of the leaders stands out for his particular synthesis of traits and life styles that are partly idiosyncratic, partly stereotypical, and partly archetypical. Let's look at the dramatis personae as a sort of preface: "Bones," with his sangfroid as a former fighter-gunman now serving as town judge; Ezequiel, whose poignant marital history seems inseparable from his role as a wealthy patriarch and old-fashioned radical; Camilo, the volatile "second cacique" (town boss) and husband of the leading usuress; Toni, scion of a rival political family, accomplished assassin, and the fastest agricultural worker in town; Boni, roguish, ultra-courteous philanderer, loyal fighter in the 
vendetta, and an explicit pantheist; Melesio, furtive, vengeful, and culturally the most conservative (e.g., in clothes and language); and finally, the complex, "sentimental," and most ardently ambitious Aquiles. In this third of the book "the symbols and meanings" are synthesized into an organic whole.

To galvanize and interrelate the unique individuality of the seven strong men, there follows a "fieldnotes interlude" of raw data- "raw" in the sense of being what I recalled (with the help of notes) and typed out minutes (or, in one case, a day) after three intrinsically exciting and also irritating meetings of the agricultural commune (ejido).

The second third or so of the book (Parts II-III) deals with the recent history and structure of politics in the village of Naranja (pronounced "nahráng-hah"- - it's the Spanish word for “orange," substituted for the Tarascan name, Naranshani). More specifically, this book is about the political structure and dynamics over one generation, and the one-generational history of a politics, with emphasis on leaders, factions, and primary bonds such as friendship. The leaders and their cohorts and their foes, along with their differences, also have much in common in their feelings, for example, about ceremonial kinship and how it binds them to one another (analyzed in the first chapter in Part II). The leaders also share other, more or less political values: attachment to the land and the peasant lust for land; political ambition to control others; and habituation to smallarms violence. The next chapter ( 4 below) is devoted to the formal and informal aspects of political organization in a narrow sense (e.g., the patterns for assemblies). The last chapter in Part II is a detailed political history contextualized in several interpretations of the "cacical process." Many strands in the book as a whole are brought together in Part III, "Political Economy," which also points ahead to the more philosophical concerns in Part IV and the final chapter in the companion volume, Agrarian Revolt in a Mexican Village (Friedrich 1977).

My focus on complex persons and shifting informal politics is part of a strategy for leading the reader to greater insight and identification with the issues by ignoring some of the conventional boundaries between the individual and the cultural/economic systems, and more generally by circumventing or bridging many familiar categories and classes of description in anthropology and history. This also applies to the historical and temporal complexity of the book's orchestration; the reader who wants a simple temporal structure is invited at this time to look elsewhere.

The final third of the book, Part IV, "Experience and Methods," consists of retrospective chapters written in the 1980s. Following on the foregoing analysis, I now sketch twelve (about half) of the main methods and kinds of evidence that were used when studying Tarascan peasant leaders: for example, locally kept chronicles, the collection of gossip, the psycho- 


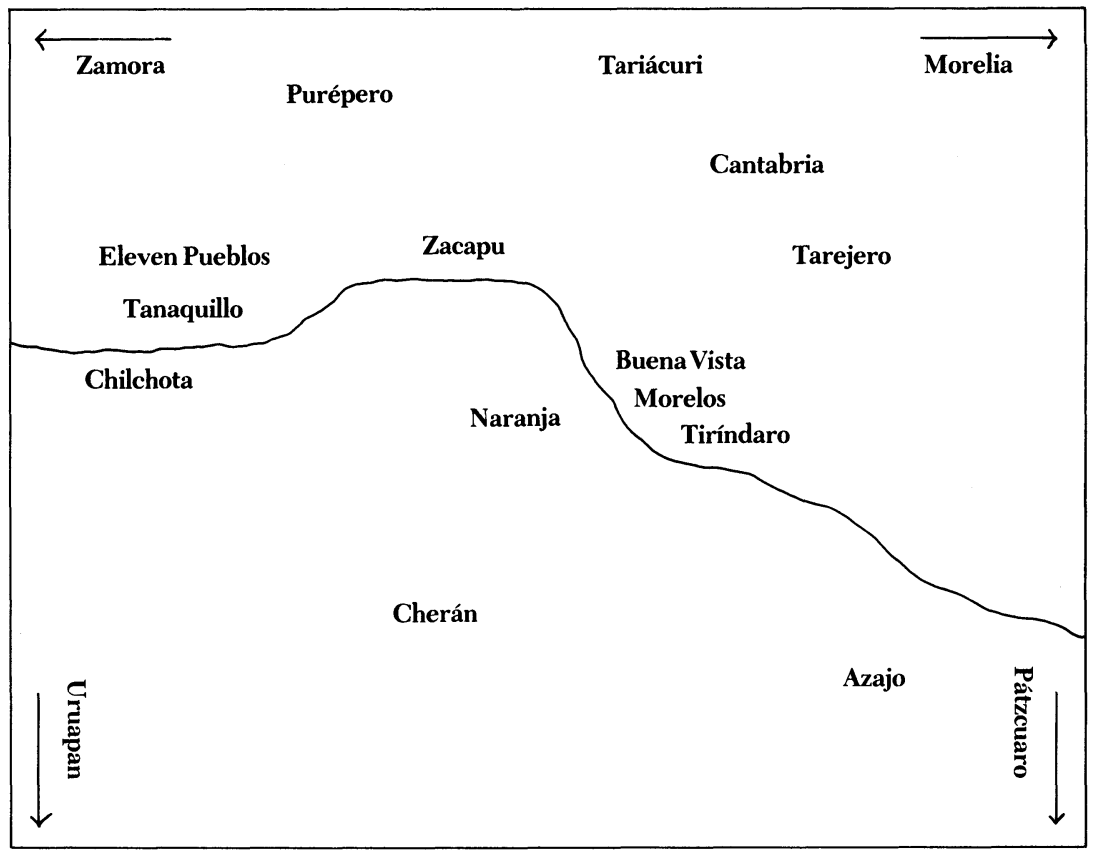

THE ZACAPU REGION AND ENVIRONS

logical interview, and the usual sort of "participant observation" by the anthrohistorian in fiestas, town meetings, and the like. Then comes a chapter on the personal experience of writing up the results of fieldwork, and a spelling out of seven "principles of composition" (for instance, what is called "partial holography"); I am told that this chapter is without precedent in the literature. The next section in this same chapter discusses the more substantive or "content" categories of an anthropological history such as the individual life history and the microsociology of primary groups (e.g., "confidential friend"). I conclude this chapter with a general model for the study of local-level politics and anthropological political history that should be of value for comparable problems, especially in the Third World. Finally, as an autobiographical postscript, there comes a chapter on the minimal, relevant facts in the anthropologist's life prior to fieldwork: what experiences and education bore most directly on my "precept and practice"? What sort of interpretive apparatus was interacting with a partly Indian culture? This is, in short, a sort of intellectual portrait of the fieldworker to match up with the leaders being studied. In a somewhat novel manner, then, the observer has been seen as part of the field or universe of observation. 
I am concerned, then, with the fieldworker, the experience and the techniques of fieldwork, the individuals, groups, and cultures being studied in the field, the stylistic, tactical, and theoretical problems of writing a fieldwork-based book, and implicitly with the potential audiences for such a book-all of which leads into questions that are unanswered and surely to some extent unanswerable. As for the "natives" in these equations, I would emphasize that I early on discarded the idea of a "paid informant," and indeed of "informant" itself at a time when these terms were standard fare, and relied instead on friends, acquaintances, or helpersor just folks who felt like being helpful for a few minutes or even hours. There are more boring ways of spending one's spare time than chatting about local politics with a curious and likable gringo. I made this tactical change partly for financial reasons: at about $\$ 90.00$ a month with a wife and two infants I simply could not afford to pay "informants." But necessity soon became a virtue as I realized the intellectual, emotional, and practical advantages of not alienating the villagers by applying the usual methods. After all, didn't Juan Belmonte revolutionize bullfighting because he had to, because he was lame?

The Princes of Naranja is a sequel or companion volume to Agrarian Revolt in a Mexican Village, which has become a classic case study in political anthropology and the anthropology and local history of Central America. The earlier book, dealing with the village and its region through fifty years of agrarian history, raised issues about local politics and agrarian reform that are basic to our understanding of peasants and farmers all over the world (including the United States, where large numbers of family farmers continue to be forced off their land every year by agribusiness and its associates). Agrarian Revolt was theoretically relevant in terms of the problematic interface between a changing economic and political system, on the one hand, and, on the other, the character of leaders, notably the colorful, violent, and psychologically complex Primo Tapia. The earlier study is now carried forward and, as it were, capped by considering leadership, ideology, factionalism, and agrarian economics in the "eth-

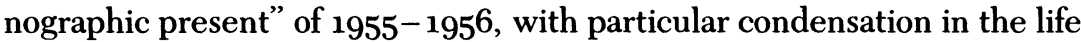
histories. At another level, both of these works are structured in terms of the trilogy of biography, ethnography, and historiography and exemplify the possibilities of interaction between the individual/personal, the social/cultural, and the historical. It is intriguing that an anthropological history mainly researched thirty years ago should be "flush with some of the basic theoretical concerns today (1985)," as one reader put it. Moreover, the patterns of caciquismo analyzed below have if anything expanded and intensified in Mexico, thereby felicitously enhancing the relevance of this book. 


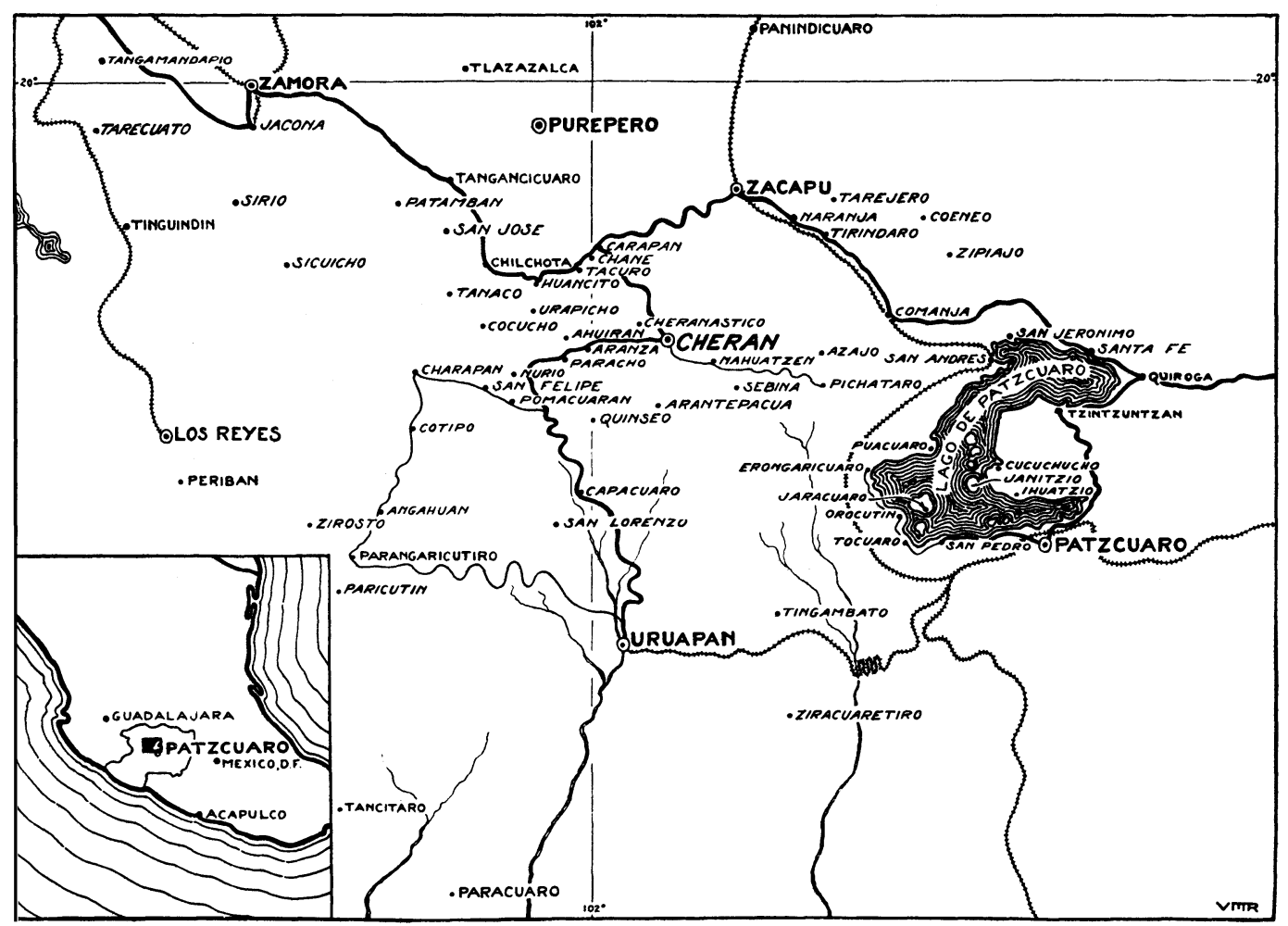

TARASCAN TERRITORY. Towns in italic are Tarascan in culture and speech. Towns in roman are either of mestizo origin or are primarily mestizo in population and culture and Spanish in speech. The inadequacies of existing maps make it difficult to show all the Tarascan towns with accuracy. Reproduced with permission from Beals 1946:6.

The first two-thirds of the book, describing local-level politics in anthrohistorical terms, has been drawn from the second volume of my 1957 doctoral thesis, Cacique: The Recent History and Present Structure of Politics in a Mexican Village, plus diverse subsequent workings, notably in 1965-1966 and 1985-1986, some of which appeared in published and anthologized articles, plus a swatch of fieldnotes added in the 1980s (for a full chart of the times of input, see Chapter 8). Personal names have been altered except for those of a few historically salient persons, notably Joaquín de la Cruz and Primo Tapia, who figure in Agrarian Revolt and largely as a consequence of that seem to have entered the larger stream of Mexican history and (political) anthropology and, indeed, have become the subject of a not inconsiderable amount of additional academic study. 
Skeletal Chronology of Key Political Events

$\begin{array}{ll}1900-1920 & \begin{array}{l}\text { Mestizo cacicazgo; agrarian movement initiated under Joaquín } \\ \text { de la Cruz }\end{array} \\ 1919 & \text { Joaquín de la Cruz assassinated } \\ 1926 & \text { Primo Tapia assassinated; breakup of regional unity } \\ 1928 & \text { Tomás Cruz assassinated; first partition of Naranja ejido } \\ 1931 & \text { Second partition of Naranja ejido } \\ 1935 & \text { Expropriation of the first group of ejidatarios } \\ 1937 & \text { Caso faction divides against itself } \\ 1941 & \text { Expropriation of the second group } \\ 1945 & \text { Attempt to overthrow Scarface, led by Martín } \\ 1952-1955 & \text { Major fission led by Juan Nahua } \\ 1955-1956 & \text { Maximum centralization under Scarface }\end{array}$

My theoretical-ideological statement in Agrarian Revolt (pp. xii-xiii) merits paraphrase here because it is, if anything, more relevant to The Princes. No one can study agrarian politics without becoming emotionally and morally involved. This is partly because the peasants themselves are deeply preoccupied with factionalism, political violence, land disputes, and some subset of the diverse historical details that bear on today's situation. Any one peasant spends far more time, energy, and thought on agrarian questions than one would guess from the anthropologies and histories, which typically dispatch the subject in a few pages or a chapter (granted recent exceptions such as Frans J. Schryer's The Rancheros of Pisaflores). Since I have bucked a number of scholarly traditions and tried to write completely, trenchantly, and sensitively on subjects about which most peasants feel strongly, it is fitting to state two relevant values of my own.

First, peasants have a right to the land around their villages, especially if there is a tradition or history of such ownership or usufruct. I approve of land reform in such cases, that is, of expropriation and redistribution. The need is real and the reform just, whether or not connected with anarchism, socialism, or any other ideology that may be held to be objectionable in some societies. But peasants also have a right to some sort of equity in the distribution of that land among themselves. The attempts of leaders to arrogate large amounts of land to themselves contradict the same laudable principles of agrarian reform.

Perhaps as important as the moral and humanistic problems is the sci- 
entific (here anthropological) historical one. A basic assumption of mine (elaborated more fully in Chapters 8 and 9) is that history and structure are determined by a complex of causes and contexts that include the natural environment; the economic relations of production and consumption; the organization of symbols we anthropologists call "culture"; the psychological factors of emotion, cognition, and character; and, finally, the more or less explicit ideologies by which people order their political lives. These and other things interact in a vast universe of (mainly mutual) implications and determination, although we may, for scientific reasons, zero in on a limited problem. Thucydides, "the first scientific historian," probed the causes of the Peloponnesian Wars. I, to some extent following him, have been deeply and indeed passionately concerned to anatomize and demonstrate the workings of one remarkable case of local-level politics, particularly its factionalism and leadership.

My debts are diverse. The research was supported financially by a starter grant of $\$ 1,500.00$ from the Wenner-Gren Foundation, a Buenos Aires Convention Fellowship from the Mexican Government $(\$ 90.00$ per month), a small loan from my father, and, during some of the write-up, allotments from the Lichstern Fund. My former wife Lore Friedrich twice typed most of the 1957 doctoral manuscript that underlies the later drafts in the first two-thirds of the book, and discussed parts of it with me. Lois Bisek retyped the entire text in 1984. Part IV was read in various sections to University of Chicago audiences, and I am grateful for the helpful comments made on those occasions. For their critical readings and suggestions on this part-made on the much different 1982 versionI wish to thank David Brent, John Comaroff, Ray Fogelson, my wife Deborah Friedrich, David Koester, David Price, James Redfield, Milton Singer, and George Stocking. Deborah gave valuable advice on three of the life studies, as did Ray Fogelson, Margaret Hardin, David Schneider, Marc Swartz, and Melford Spiro on "Bones" and "Camilo." Deborah and Fred Strodbeck commented astutely on the chapter which analyzes small group relations, as did Paul Liffman on this and Chapter 5, and John Attinasi, Deborah, Tim Buckley, and Lloyd Rudolf on Chapter 9. Dale Arntson read and critiqued Parts II and III. Gail Mummert-Zendejas, through her thesis, her questions, and her detailed answers to my questions, provided an invaluable factual backstop to the enterprise, as well as some fascinating information and insight into Naranja in the early eighties. The entire text of the book was reviewed, that is, read aloud and intermittently discussed, in a special seminar on anthrohistory at the University of Chicago, and I am grateful to the students for their questions: Pat Allen, Bruce Applebaum, Dale Arntson, Coby Jones, Valerie Hector, Laura Lewis, Paul Liffman, and Robert Moore. Economist Kenneth Miranda helpfully checked out the economics at the eleventh hour. All parts of the 
xx Preface

book profited from the earlier comments of Sidney Mintz, and Friedrich Katz made some strategic suggestions. My more generic intellectual debts for the point of view in the work as a whole are to the anthropologists Clyde Kluckhohn and Ralph Linton, and to my father, Carl Friedrich.

PAUL FRIEDRICH

Chicago, 1986 